\title{
EnCity: A serious game for empowering young people with Down's syndrome
}

\author{
Bourazeri, A, Bellamy-Wood, T \& Arnab, S
}

Author post-print (accepted) deposited by Coventry University's Repository

Original citation \& hyperlink:

Bourazeri, A, Bellamy-Wood, T \& Arnab, S 2017, EnCity: A serious game for empowering young people with Down's syndrome. in 2017 IEEE 5th International Conference on Serious Games and Applications for Health (SeGAH). IEEE, International Conference on Serious Games and Applications for Health, Perth, Australia, 2-4 April

https://dx.doi.org/10.1109/SeGAH.2017.7939267

$\begin{array}{ll}\text { DOI } & 10.1109 / \text { SeGAH.2017.7939267 } \\ \text { ISBN } & 978-1-5090-5483-1 \\ \text { ESBN } & 978-1-5090-5482-4\end{array}$

Publisher: IEEE

(C) 2017 IEEE. Personal use of this material is permitted. Permission from IEEE must be obtained for all other uses, in any current or future media, including reprinting/republishing this material for advertising or promotional purposes, creating new collective works, for resale or redistribution to servers or lists, or reuse of any copyrighted component of this work in other works.

Copyright $(\subseteq$ and Moral Rights are retained by the author(s) and/ or other copyright owners. A copy can be downloaded for personal non-commercial research or study, without prior permission or charge. This item cannot be reproduced or quoted extensively from without first obtaining permission in writing from the copyright holder(s). The content must not be changed in any way or sold commercially in any format or medium without the formal permission of the copyright holders.

This document is the author's post-print version, incorporating any revisions agreed during the peer-review process. Some differences between the published version and this version may remain and you are advised to consult the published version if you wish to cite from it. 


\title{
EnCity: A Serious Game for Empowering Young People with Down's Syndrome
}

\author{
Aikaterini Bourazeri*, Tyrone Bellamy-Wood and Sylvester Arnab \\ Disruptive Media Learning Lab \\ Frederick Lanchester Library \\ Coventry University \\ Coventry, CV1 5DD \\ *Email: aikaterini.bourazeri@ coventry.ac.uk
}

\begin{abstract}
Down's syndrome (also known as trisomy 21) is a genetic disorder caused by the presence of a third copy of chromosome 21 in a baby's cell. With education and proper care the quality of life of these people can be improved, and with the right support people with Down's syndrome can have an active role in the community. In this paper we examine how a virtual reality serious game, the EnCity game, could engage and encourage young people with Down's syndrome to have a more active involvement in the community. Players should complete mini games related to everyday tasks (e.g. preparing a meal, shopping in the supermarket, paying a bill, buying a ticket to visit a museum or gallery), and through these mini-games players will gain the appropriate training and encouragement for leading their lives without requiring help from their families or social services.
\end{abstract}

Keywords - Down's syndrome, empowerment, inclusivity, serious games.

\section{INTRODUCTION}

Down's syndrome is a genetic disorder caused by the presence of a third copy of chromosome 21 in a baby's cell. According to Down's Syndrome Association, one in every thousand babies is born in the UK with Down's syndrome. 750 babies with this syndrome are born each year, and there are approximately 40,000 people in the UK with this disorder [1]. The quality of life, life expectancy and their role in the community have significantly changed over the years as education and support have been improved. There are now more opportunities for these people to live an independent life, but still more work remains to be done to ensure that they have the same opportunities as the general population.

There is a small but increasing percentage of people with Down's syndrome who lead their lives and leave their family homes, however the lack of their empowerment and inclusivity in the community prevents a large amount of these people from enjoying everyday life experiences and having a fully independent life. The majority of them choose to stay with their families and meet their needs from social services. People with Down's syndrome typically have learning disabilities, but with appropriate teaching and training they can have an active role in the community and reach their goals.

Serious games have proved to be an effective and engaging mechanism for people with disabilities [2], [3]. These serious games should be configurable and adaptable to users' needs providing at the same time a personalised environment that would motivate them and capture their attention over the longterm. In this paper we propose the development of a virtual reality (VR) game, the EnCity game, for empowerment and inclusivity of people with Down's syndrome into the society.

The development of this serious game will provide the required education, training and motivation, and therefore people with disabilities will succeed in having an autonomous and vital role in the community. In an animated environment which portrays a typical city with services and amenities such as post office, health centre, bank, supermarket, pharmacy and so on, people will undertake real-life activities (e.g. shopping, banking transactions, visits to doctors, museums or libraries, etc). At the end of the game, people will have acquired the required training and also motivation to pursue an independent life and be active members of our community.

This paper is structured as follows. In Section II we introduce Down's syndrome and the role of people with this disorder in the community. Section III presents serious games and how they can be used as an effective mechanism for teaching and learning, and reviews several serious games that have been developed for people with cognitive disabilities. Section IV presents the game mechanics and aesthetics, and proposes a new interface design for EnCity game. Section V presents some limitations and the future work for EnCity game and we conclude in Section VI with some remarks about how empowerment and inclusivity can enable people with Down's syndrome.

\section{DOWN'S SYNDROME}

Down's syndrome is a genetic disorder which is neither an inherited condition nor a disease as people with Down's syndrome do not suffer from this condition. In 2013, 8.5 million of individuals were recorded with this syndrome worldwide. People with the syndrome typically have learning disabilities without implying, however, that they cannot learn at their own pace. Education and proper care can improve the quality of their life and with the right training these people can have a dynamic role in our community (in USA $20 \%$ of these adults do paid work) [4]. Education and support have improved the quality of life of these people, and their life expectancy has been increased. Many of the children with Down's syndrome 
attend their local mainstream schools, while others may require a more specialised education [5].

The majority of young people with this syndrome choose to stay with their families and meet their needs from social services. Independent living may not be a realistic option for many people with Down's syndrome, however if an enriched and inclusive community is provided, these people will develop self-respect and a positive attitude towards daily activities. There are now more opportunities for these people to live an independent life, but still more work should be done to ensure that young people with Down's syndrome lead their lives away from their family homes and enjoy the general population life experiences.

If people with Down's syndrome are to have a good quality of life, they should make their own choices and be given the opportunity to be responsible for their life and function effectively in their community. Providing choices and opportunities to these people will help us understand what really prevents them from a social inclusion and also what are their individual needs, interests and abilities. Developing new skills and abilities for independent living and social inclusivity will minimise the gap between people who have semi-skilled or skilled, part-time or full-time jobs and those who do not have access to a working environment. Constant education and learning are very important for developing problem-solving skills and personal control. With further government policies and regulations, community support and encouragement, people with Down's syndrome will have an active and agile role in our community [6].

\section{Serious Games \& Cognitive Dis abilities}

Serious games are digital games, simulations and virtual environments widely used for primary purposes (e.g. teaching, learning and training) other than pure entertainment. They are experiential environments where features such as communication, negotiation, leadership or time management are as important, if not more than fun or entertainment [7]. Serious games are met quite often in military, government and healthcare with extensive use in education and learning as they are engaging and appealing to all people despite their age or background [8], [9], [10]. They are user-centric and players are actively involved in situations and scenarios relevant to their 'real-life' circumstances. Trying to achieve the game's objectives, users practise their skills, methodologies and acquired knowledge in a realistic environment and understand the implications and consequences of their actions without facing real-world impacts. Serious games encourage users not only to learn but also to apply their knowledge [11]. Users are encouraged to make mistakes while they play, as the key objectives are learning, knowledge retention, understanding of new concepts, problem-solving and real-time data analysis.

Focusing on intrinsic learning, serious games are the missing link between knowledge and practice; users develop awareness and skills, and charge their behaviour accordingly in order to take control of their actions and achieve their objectives. Users are at the centre of action and therefore they learn at their own pace and evaluate their outcomes in their own time without peer pressure [12], [13]. Learning and personal development are now more enjoyable and users only progress when they have mastered in knowledge or skills. These graphical environments with 'real-life' settings convey messages in a more meaningful and interesting way enabling users to relate the game concepts to their daily life. Serious games are very effective in teaching and training as they communicate the learning objectives in a very efficient and productive way.

Serious games have proved to be an effective and engaging mechanism for people with disabilities [2], [3]. These serious games should be adaptive and adjustable to users' needs and preferences, providing at the same time a personalised environment which triggers learning and captures the attention for long-term. People perceive games according to their disabilities, interests, skills and capabilities. A serious game for people with cognitive disabilities should minimise the accessibility obstacles, use simple and direct language, allow enough time during the gameplay and every action should be followed by feedback [14]. Some of the tasks these games target include meal preparation, cleaning, laundry, time and money management, road skills and so on. e-Adventure game authoring tool [15] is used to create games for people with cognitive disabilities with main emphasis on their education in order to increase the opportunities for their employment.

"My first day at work" educational game [16] encourages the workers' embodiment in a new company. In this game players have already been employed and are taught the required skills and competencies for a successful integration into their team. Players should use the standard equipment and materials available in the office such as computers, printers and fax, learn how to read incoming emails, compose and send new emails and download files. Players also learn basic social interaction skills such as how to talk to colleagues with respect and ask them for advice and help. This game is an adventure quest and players should complete different tasks assigned by the company's management board by interacting with different objects and characters. Different accessibility features (e.g. control the game using the mouse, keyboard or speech commands and receive feedback either visually or by audio) help players with visual disabilities or limited hand mobility.

"The Big Party" game [16] exhibits social and selfautonomy skills and concepts for adults with cognitive disabilities. Players should attend a social dinner organised by the company they work for. Players choose their character and the game adapts the available clothes and hygiene habits to the specific character chosen. They should complete tasks in specific order relating to personal hygiene such as having a shower, putting cologne and deodorant, brushing teeth and hair, preparing before leaving home (i.e. put appropriate clothing, use the public transport to arrive to the event, use common resources in public places such as ticket vendor machines and use of appropriate language and behaviour in formal events). Players should complete these tasks in a specific order and 
receive feedback based on their actions. The overall goal of the game is to prepare players with cognitive disabilities for professional development.

Flexibility Learning on the Web (FLOW) project [17] develops interactive, multi-player web-based games to enhance social interaction in children with high-functioning autism and Asperger's. In a simple 3D environment, children should cooperate with each other to solve problems and successfully complete activities and games. Players control their avatars using the arrow keys and pick up and drop objects using the spacebar. In one activity, players work with objects with two or three features such as shape, colour and pattern and should select the object that is the same as the one selected by the leader of the team they belong to.

A virtual world consisting of a house with six rooms and a tree in the backyard as a meeting place was created to teach fire and street safety to children diagnosed with fetal alcohol syndrome (FAS) [18]. A virtual dog named Buddy shows to players the correct actions in small and incremental steps and provides feedback based on their actions. Players move in the virtual world using the keyboard arrow keys. Every time the player does an action that is not allowed, such as walking into a fire or stepping into the street without looking, the screen becomes black and the danger is explained. When the player fully understands the risk, s/he can continue playing.

The Autism Project's [19] objective is the implementation of a software and hardware system that could help children with autism during the rehabilitation process by providing them personalised activities in the form of educational games. During the game, the child's actions are monitored for a better understanding of his/her behaviour. A proposed multiagent system architecture encourages children to interact with different agents related to the activities they have to undertake and their educational context. During the game, the child is supported by three agents; the user observation agent which observes the child's actions and gives access to system's resources, the tutor agent which is mainly a didactic agent and the exceptions management agent which ensures interactivity between the child and the tutor agent.

The unique characteristics of serious games make them effective in teaching and learning. In a safe environment, users explore the virtual world at their own pace, experiment with the different tasks and activities and receive real-time feedback. Serious games have many advantages for people with cognitive disabilities; people get engaged with the virtual world, improve their skills and knowledge and they do not face consequences when they do something 'wrong'. Designing an effective serious game for young people with Down's syndrome has many constraints; the population is heterogeneous and it is difficult to be categorised and modelled, and therefore due attention and research is required to ensure that the proposed learning will be achieved.

\section{ENCITy GAME}

The Intervention Mapping (IM) approach [20] was followed during the design and development phase to ensure that the methodologies and tools used for the implementation of the EnCity game are adaptive to the characteristics, needs and capabilities of young people with Down's syndrome. IM methodology (see Figure 1) was modified accordingly to ensure that EnCity game encapsulates both the preferences and requirements of the intended players, and in collaboration with Down's Syndrome Association to design a game that is grounded both on evidence and theory [21]. The Agile methodology [22] is used to provide a flexible game design which rapidly responds to the requirements and changes proposed by the end-users and stakeholders. Each mini-game has numerous iterative cycles (sprints) to ensure the continuous improvement and evolutionary development of the EnCity game.

Figure 2 presents the EnCity game architecture. The game engine is responsible for visualising the game world and enabling the game's dynamics and interactivity. We use Unity game engine which supports Google VR, can be fast deployed for many platforms and can be optimised for various low and high powered devices. VR technology is widely used in cognitive disabilities and there is an extensive use in the area of motor learning for people with Down's Syndrome. VR has proved to be an effective means for achieving rehabilitation intervention as therapy is provided within a functional, purposeful and motivating context [23]. VR features such as immersive virtual worlds, real-time feedback and different levels of difficulty adapted to players' capabilities are useful and essential elements for cognitive disabilities [24], [25]. In the game engine the different animations, pathfinding (the ways in which characters move around in the world and avoid barriers), state of the game, feedback system and assets are defined. To avoid accessibility barriers and enable simple route access in the game, large areas of open space have been included. The game loop handles all the players' inputs and the state of the game, and the game framework is responsible for the game interface and players' inputs [26].

\section{A. Game Design}

In EnCity game, the player is a first-person character (firstperson perspective) to allow for better movement-control and easier aiming. Players cannot see the avatar's body but through the avatar's eyes they can explore the world, participate in individual and group activities, interact with in-world objects, build and create other objects [27]. First-person character increases the level of immersion in EnCity game and encourages players to become a key part of the virtual world; players are the main game characters who interact with the different objects and complete the tasks.

Players control their characters through a point-and-click interface which is often used in games for people with cognitive disabilities as low-paced movement and control are desirable characteristics in such games [16]. Choosing the point-andclick mechanics minimises the number of accessibility barriers that young people with Down's syndrome may face when playing the EnCity game. The point-and-click mechanic limits dramatically the game interactions, however this mechanic with the single button control is appropriate for our target 


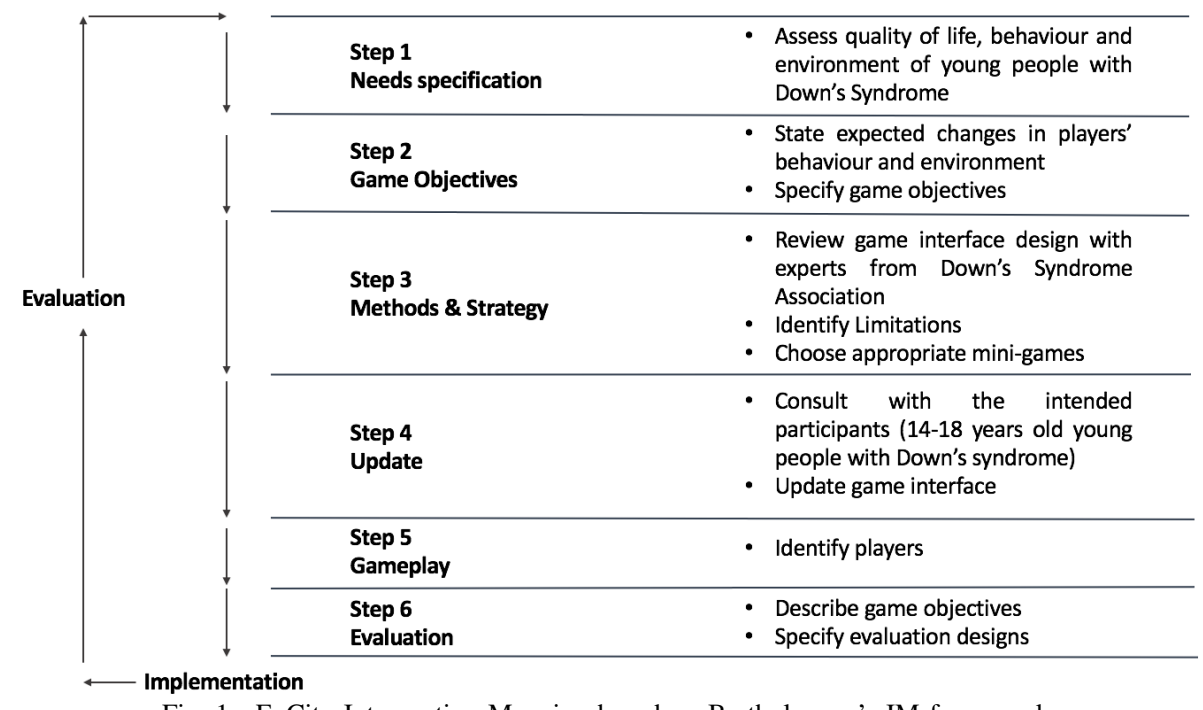

Fig. 1. EnCity Intervention Mapping based on Bartholomew's IM framework.

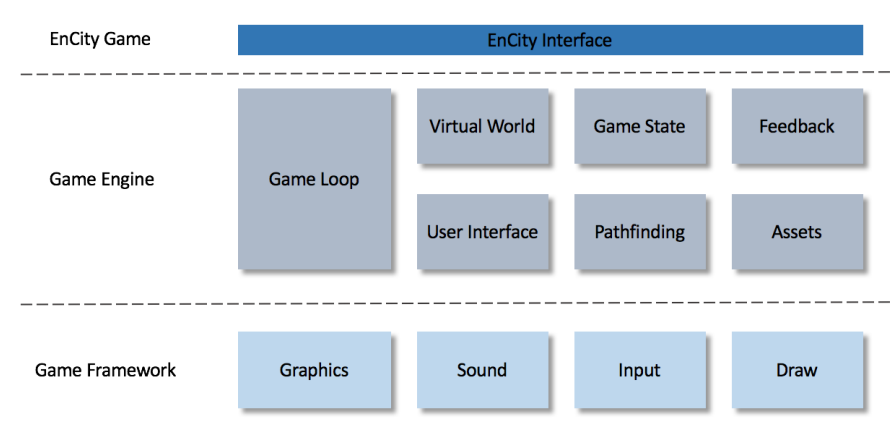

Fig. 2. EnCity game architecture.

players. Other game mechanics such as points, levels, challenges and virtual goods have been included to increase the player's engagement and immersion. Players click to move around, explore the virtual world and examine the available objects using a VR headset such as the Google Cardboard.

The goal of this game is to empower and support young people with Down's syndrome to have an independent and autonomous life. Different mini-games, developed as separate scenes, teach players various skills and help them experiment and familiarise themselves with everyday tasks such as choice of the right fruits, vegetables and ingredients in the supermarket, food preparation (e.g. follow the recipe and choose the right ingredients and pots), fire safety, money transactions in the bank and post office and so on. In the first minigame for cooking (see Figure 3), the player should prepare a meal using the available ingredients in the kitchen. The player follows a visual instructional checklist (recipe) and should use fresh ingredients for a high quality food which will give him/her more points. This mini-game measures player's ability to follow instructions and choose high quality products. As the player progresses in this mini-game, recipes become more complex and the instructional checklist includes more steps. Players can repeat a specific recipe and can choose to

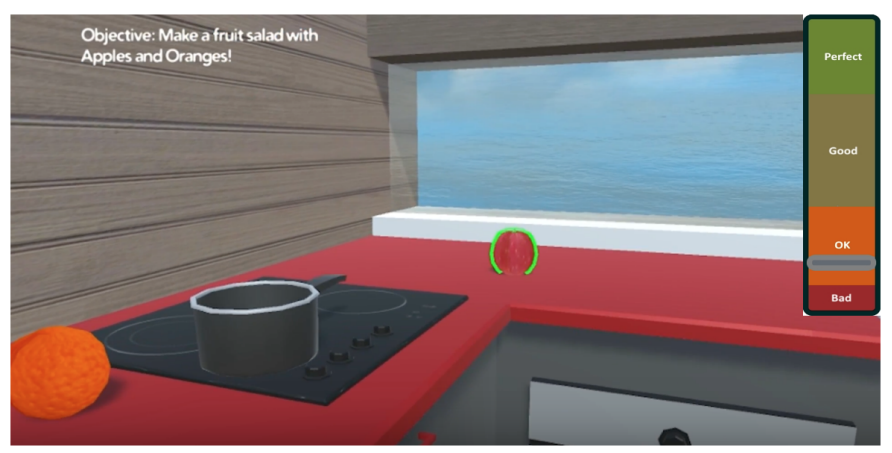

Fig. 3. EnCity Cooking mini-game.

cook without following instructions to gain more points. The overall rating is affected by the quality of the cooked food. An appraisal meter has been included which acts as a bonus points meter. When players have a good appraisal rating, they can earn experience points which unlock more recipes.

On the left side corner of the game interface, a list with the objectives that players should complete is always visible to help people who cannot remember short-term goals. Specific aesthetic design patterns such as shading and material types have been included in the game to give the scene a more realistic look, engage players and trigger immersion. These design patterns emphasise certain objects as key items (e.g. fruit) without distracting the player from the primary objective (e.g. make a fruit salad).

\section{B. Interface Design}

The EnCity interface design is user-centred with the emphasis being on users' needs, preferences and limitations as identified by the Down's Syndrome Association. This usercentred interface design is characterised by a multi-stage problem solving process [28] which will constantly improve the interface around users' preferences and needs, and will not force users to change their behaviour in order to adapt to 


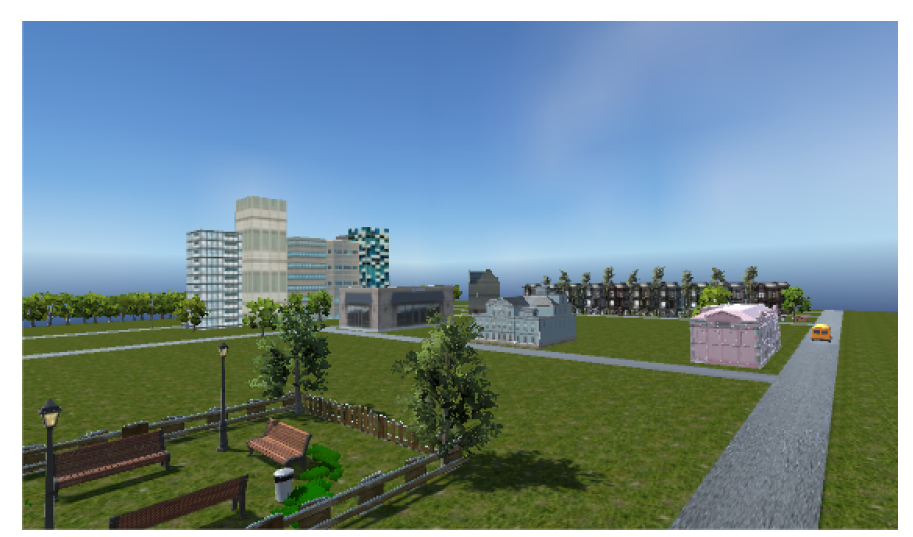

Fig. 4. EnCity game interface.

our proposed interface. Explicit understanding of the target groups, their skills and capabilities is a pre-requisite for the interface design, and therefore constant communication and collaboration with the Down's Syndrome Association is required.

EnCity game represents a typical city (see Figure 4) with services and amenities such as post office, health centre, bank, supermarket (see Figure 5), pharmacy and so on. EnCity game replicates and gamifies real-world activities, and challenges players through everyday tasks such as preparing a meal, shopping in the supermarket, paying a bill, buying a ticket to visit a museum or gallery. Undertaking such real-life activities in an animated world, players learn and develop real-world skills.

This virtual world includes customisable houses and buildings, vehicles, animals and parks to increase playability. Playability is a game's attribute which provides entertainment and joy, and can be measured through a set of properties that define the player experience. One of these properties is satisfaction; the degree of pleasure that players feel when the game is completed. Satisfaction in EnCity game depends on players' preferences with regards to their houses, the game environment and rewards [29]. EnCity is an easy-to-understand game (e.g. game rules, objectives and system resources) and the learning curve is always adapted to players' needs and preferences. EnCity provides sufficient time and resources to players in order for them to adapt to the environment, explore the world and complete their tasks. Our target players are young people with Down's syndrome and therefore they should reach their goals without overcoming their abilities. Players should remain motivated and encouraged throughout the game to easily complete their tasks and defeat any occurred challenges.

\section{LiMITATIONS \& FUTURE WORK}

Further interviews with experts from the Down's Syndrome Association and constant engagement with the end-users (i.e. young people with Down's syndrome) are required to address the current limitations of our work regarding the mini-games' development. There are several aspects of development we

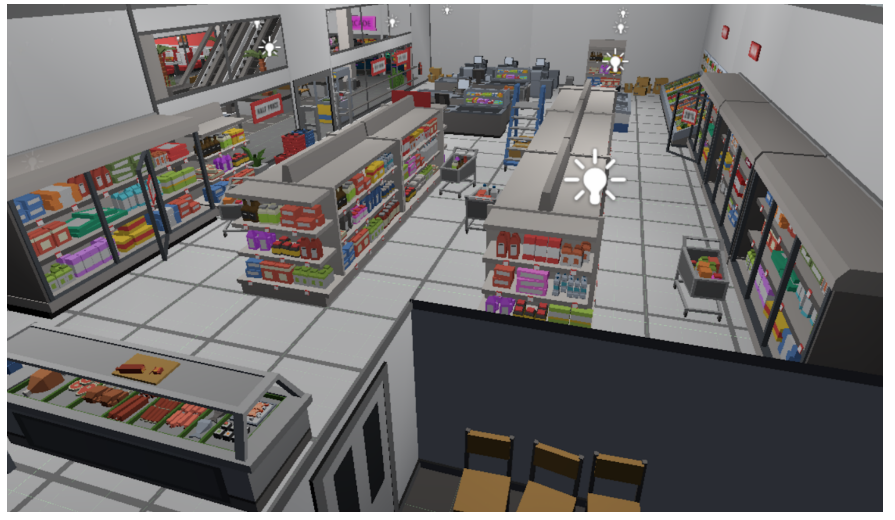

Fig. 5. A supermarket in EnCity.

consider for future work. These include the improvement of the EnCity interface with additional features to make the virtual world more realistic and engaging. Additional minigames will be included to help people with Down's syndrome to familiarise themselves with even more everyday tasks.

Accessibility issues will be addressed to ensure that EnCity is an enjoyable and fun game that helps people develop skills such as decision-making, critical thinking and analytical skills. The difficulty level of the mini-games will be adaptive to the player's performance. All areas of the game interface should be accessed using the same input method (i.e. point-and-click) and the interactive elements should be large and well-legible.

As it was mentioned above, the use of serious games can be an effective mechanism for teaching and training. Through serious games, people with Down's syndrome can build essential life and work skills without suffering the consequences of 'wrong' actions. In EnCity, these people will learn how to avoid problems and take better actions and decisions regarding real-life problems, while they could develop social and cognitive skills and gain the required confidence to engage with everyday life activities. Users will explore new activities and experiences, communicate with inworld players and practise new skills [30], [31]. At the end of the game, players receive real-time feedback based on their actions which challenges their critical thinking and problemsolving skills[32].

EnCity game combines learning with fun and recreation. Without extrinsic motivation that forces learning, this game will actively engage players. Creativity is promoted tremendously as players can customise their houses. EnCity will be a process to learning rather than a predicted outcome [33] which stimulates and supports skills development and active involvement in communities.

\section{CONCLUSIONS}

The digital world is full of ideas, thoughts, choices and learning opportunities available to "anyone anytime anywhere". In this digital world, serious games are continually developing and used in education, business, government, healthcare and (physical) recovery. In serious games, teaching 
and learning are the leading factors with entertainment being only a supportive element. Accessibility is an important issue in educational and healthcare games as people who play these games have a certain disability such as colour blindness or hearing impairment. Recent innovations in serious game development try to provide accessibility to everyone and various serious games have been developed for people with cognitive disabilities [34].

The main contribution of this paper is to propose a VR serious game, the EnCity game, for young people with Down's syndrome in which players have to complete different minigames to help them experiment and familiarise themselves with everyday tasks such shopping, food preparation, money transactions and so on. Using a serious game for empowerment and inclusivity, people with Down's syndrome will be encouraged to lead their lives and have a more active role in our society.

Serious games are an effective mechanism for teaching and learning as players explore the virtual world at their own pace, experiment with the different tasks and activities and receive real-time feedback. Serious games can engage people with cognitive disabilities, improve their skills and knowledge and trigger their problem-solving skills. These games can prepare people with disabilities for an independent life without needing support from social services.

\section{ACKNOWLEDGEMENTS}

This work is supported by H2020 BEACONING project (687676).

\section{REFERENCES}

[1] (2016) Down's syndrome association. [Online]. Available: http://www.downs-syndrome.org.uk/

[2] L. Evett, A. Ridley, L. Keating, P. Merritt, N. Shopland, and D. Brown, "Designing serious games for people with disabilities: Game, set, and match to the wii?" Gamification for Human Factors Integration: Social, Education, and Psychological Issues: Social, Education, and Psychological Issues, p. 97, 2014.

[3] D. J. Brown, D. McHugh, P. Standen, L. Evett, N. Shopland, and S. Battersby, "Designing location-based learning experiences for people with intellectual disabilities and additional sensory impairments," Computers \& Education, vol. 56, no. 1, pp. 11-20, 2011.

[4] L. Szabo. (2013) Life with down syndrome is full of possibilities. [Online]. Available: http://www.usatoday.com/story/news/nation/2013/05/01/life-downsyndrome-improving/2054953/

[5] E. Avramidis, P. Bayliss, and R. Burden, "A survey into mainstream teachers' attitudes towards the inclusion of children with special educational needs in the ordinary school in one local education authority," Educational psychology, vol. 20, no. 2, pp. 191-211, 2000.

[6] R. Brown, Life for Adults with Down syndrome: An Overview. DSE Enterprises, 2004.

[7] T. Marsh, "Serious games continuum: Between games for purpose and experiential environments for purpose," Entertainment Computing, vol. 2, no. 2, pp. 61-68, 2011.

[8] S. Marks, J. Windsor, and B. Wünsche, "Evaluation of game engines for simulated clinical training," 2008.

[9] R. Bulander, "A conceptual framework of serious games for higher education: Conceptual framework of the game innov8 to train students in business process modelling," in e-Business (ICE-B), Proceedings of the 2010 International Conference on. IEEE, 2010, pp. 1-6.

[10] A. Hulst, T. Muller, S. Besselink, D. Coetsier, and C. Roos, "Bloody serious gaming: experiences with job oriented training," in Proceedings: Interservice/Industry Training, Simulation, and Education Conference (I/ITSEC), 2008.
[11] D. R. Michael and S. L. Chen, Serious games: Games that educate, train, and inform. Muska \& Lipman/Premier-Trade, 2005.

[12] S. Freitas and H. Routledge, "Designing leadership and soft skills in educational games: The e-leadership and soft skills educational games design model (eless)," British Journal of Educational Technology, vol. 44, no. 6, pp. 951-968, 2013.

[13] H. Routledge, "What's next for serious games?" in Why Games Are Good For Business. Springer, 2016, pp. 190-202.

[14] R. M. Tomé, J. M. Pereira, and M. Oliveira, "Using serious games for cognitive disabilities," in International Conference on Serious Games Development and Applications. Springer, 2014, pp. 34-47.

[15] J. Torrente, Á. Del Blanco, E. J. Marchiori, P. Moreno-Ger, and B. Fernández-Manjón, "e-adventure: Introducing educational games in the learning process," in IEEE EDUCON 2010 Conference. IEEE, 2010, pp. 1121-1126.

[16] J. Torrente, Á. Del Blanco, P. Moreno-Ger, and B. Fernández-Manjón, "Designing serious games for adult students with cognitive disabilities," in International Conference on Neural Information Processing. Springer, 2012, pp. 603-610.

[17] P. Ohring, "Web-based multi-player games to encourage flexibility and social interaction in high-functioning children with autism spectrum disorder," in Proceedings of the 7th international conference on Interaction design and children. ACM, 2008, pp. 171-172.

[18] C. D. Coles, D. C. Strickland, L. Padgett, and L. Bellmoff, "Games that "work": Using computer games to teach alcohol-affected children about fire and street safety," Research in developmental disabilities, vol. 28, no. 5, pp. 518-530, 2007.

[19] K. Sehaba, P. Estraillier, and D. Lambert, "Interactive educational games for autistic children with agent-based system," in International Conference on Entertainment Computing. Springer, 2005, pp. 422-432.

[20] L. K. B. Eldredge, C. M. Markham, G. Kok, R. A. Ruiter, G. S. Parcel et al., Planning health promotion programs: an intervention mapping approach. John Wiley \& Sons, 2016.

[21] S. Arnab and S. Clarke, "Towards a trans-disciplinary methodology for a game-based intervention development process," British Journal of Educational Technology, 2016.

[22] R. C. Martin, Agile software development: principles, patterns, and practices. Prentice Hall PTR, 2003.

[23] H. Sveistrup, "Motor rehabilitation using virtual reality," Journal of neuroengineering and rehabilitation, vol. 1, no. 1, p. 1, 2004.

[24] L. D. C. de Menezes, T. Massetti, F. R. Oliveira, L. C. de Abreu, S. R. P. Malheiros, I. L. Trevizan, C. H. Moriyama, and C. B. de Mello Monteiro, "Motor learning and virtual reality in down syndrome; a literature review," International Archives of Medicine, vol. 8, 2015.

[25] A. K. Roy, Y. Soni, and S. Dubey, "Enhancing effectiveness of motor rehabilitation using kinect motion sensing technology," in Global $\mathrm{Hu}$ manitarian Technology Conference: South Asia Satellite (GHTC-SAS), 2013 IEEE. IEEE, 2013, pp. 298-304.

[26] M. Uurloon. (2015) Design of a point and click adventure game engine. [Online]. Available: http://www.groebelsloot.com/2015/12/01/design-ofa-point-and-click-adventure-game-engine/

[27] D. Zahavi, Subjectivity and selfhood: Investigating the first-person perspective. MIT press, 2008

[28] M. Hersh and M. A. Johnson, Assistive technology for visually impaired and blind people. Springer Science \& Business Media, 2010.

[29] H. Korhonen and E. M. Koivisto, "Playability heuristics for mobile games," in Proceedings of the 8th conference on Human-computer interaction with mobile devices and services. ACM, 2006, pp. 9-16.

[30] J. Kahn and S. E. Wright, Human Growth and the Development of Personality: Social Work Series. Elsevier, 2013.

[31] C. Tickell, "The early years: Foundations for life, health and learning," An independent report on the early years foundation stage to Her Majestys Governmentmedia. education. (17.12. 2011), 2011.

[32] J. Martlew, C. Stephen, and J. Ellis, "Play in the primary school classroom? the experience of teachers supporting children's learning through a new pedagogy," Early Years, vol. 31, no. 1, pp. 71-83, 2011.

[33] B. Dietze and D. Kashin, Playing and learning in early childhood education. Pearson Canada, 2012.

[34] (2015) The accessibility argument in serious games. [Online]. Available: http://game-accessibility.com/documentation/theaccessibility-argument-in-serious-games/ 